\title{
Fermentative hydrogen production by conventionally and unconventionally heat pretreated seed cultures: A comparative assessment
}

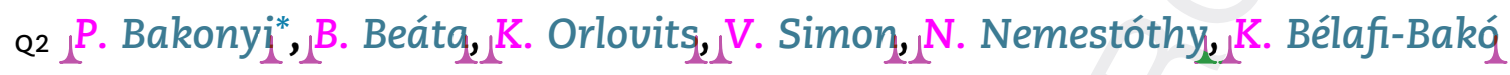
Research Institute on Bioengineering, Membrane Technology and Energetics, University of Pannonia, Egyetem Street 10, 8200 Veszprém, Hungary

\section{A R T I C L E I N F O}

Article history:

Received 27 November 2013

Received in revised form

8 January 2014

Accepted 16 January 2014

Available online $\mathrm{xxx}$

\section{Keywords:}

Biohydrogen

Sludge

Heat

Pretreatment

Microwave

Irradiation

\begin{abstract}
A B S T R A C T
In this study, the effects of pretreatment temperature and time during conventional and unconventional, microwave-assisted heat shock on the hydrogen producing capability of anaerobic seed sludge from soluble starch was focused. It was found that the different heat transfer techniques resulted in seed cultures with comparable hydrogen production potentials, with the highest obtainable values of approximately $0.9 \mathrm{~L} \mathrm{H}_{2} / \mathrm{L}-\mathrm{d}$. A comprehensive, statistical analysis revealed that both treatment temperature and time could be designated as significant process variables, however, in distinguishable extents for the two alternative methods. The results indicated that microwave-based sludge pretreatment needed remarkably shorter curing times (2 min) to eliminate $\mathrm{H}_{2}$-consuming, methanogenic activity in comparison to the conventional heat shock method (30 min). It was also demonstrated that microwave irradiation increased the soluble organic matter content in the seed sludge.
\end{abstract}

Copyright @ 2014, Hydrogen Energy Publications, LLC. Published by Elsevier Ltd. All rights reserved.

\section{Introduction}

Biohydrogen is a prosperous energy carrier that receives significant attention from the scientific research community [1]. It has the potential to contribute to a more sustainable development but probably it will only be realized in relatively long terms [2]. This is because further advances have to be accomplished in order to make it a more competitive alternative both from technological and economical points of views. One particular issue to address is related to the production yields and rates, which are among the most important criteria for the evaluation of the overall biohydrogen process economy [3]. In fact, tremendous efforts have been put to improve them both on the upstream [4] and downstream sides $[5,6]$. As a result, dark fermentative biological hydrogen generation is nowadays the most promising way to go considering these practical aspects $[7,8]$. For example, hydrogen producing microorganisms have the ability of utilizing complex feedstock, even valueless and abundant waste materials [9-11]. However, it is also quite obvious that feasible hydrogen production needs the assistance of diverse microbial population (present in biogas sludge) rather than pure cultures. Beside the benefits of mixed consortia, when such inocula are used for

\footnotetext{
* Corresponding author. Tel.: +36 88 624385; fax: +36 88624292 .

E-mail addresses: bakonyip@almos.uni-pannon.hu, bakonyipeter85@gmail.com (P. Bakonyi). 0360-3199/\$ - see front matter Copyright @ 2014, Hydrogen Energy Publications, LLC. Published by Elsevier Ltd. All rights reserved. http://dx.doi.org/10.1016/j.ijhydene.2014.01.110
} 
the bioconversion of organic substances into biohydrogen, their sufficient pretreatment is usually required to suppress the activity of undesirable species such as methanogenes, homoacetogenes, etc. which are capable to inherently cut the obtainable hydrogen turnout. These pretreatments can be performed by exposing the community of strains to unfavorable conditions e.g. to elevated temperature, which refers to heat shock. This method is the most routinely applied one for the enrichment of the hydrogen-evolver bacteria in the population since it is relatively fast, easy to conduct and highly reliable [12].

Actually, there are different kinds of this technique altering in the mode of heat transfer and distinguished as conventional and unconventional ones. In general, the application of heat shock for pretreatment purposes relies on the conventional way meaning that the sources of inocula are usually kept in a hot (even boiling water) bath. Nevertheless, unconventional heat transfer takes place due to direct energy irradiation to the media, which can be ensured by microwave irradiation [13]. In summary, the application of conventional heating for energy input is a wide-spread opportunity, however, energy transfer and its rate are dependent on the heat conductivity of both the vessel containing the reaction mixture and the reaction mixture itself. On the contrary, unconventional, microwave-aided heating is independent of such parameters [14,15].

Consequently, the possible advantage of employing microwave irradiation is that a remarkably higher power density (amount of energy input to a certain volume of reaction media in a given timeframe) can be ensured so that it may lead to a reduction in the curing times needed for efficient sludge pretreatment.

It is to note that the usage of microwave energy is emerging to enhance the digestibility of complex (e.g. lignocellulosic) raw materials so as to achieve enhanced biohydrogen fermentation performance [16-18]. However, microwave applications for seed culture pretreatment are not well studied, especially not in microwave reactors under controlled conditions as intended herewith. Up to our knowledge, the current literature is lacking a comparative assessment of the conventional $]_{\alpha}$ and unconventional heat treatments for seed enrichment purposes.

Therefore, in this work, it was aimed to investigate the feasibility and impacts of these different, conventional and microwave-assisted, unconventional pretreatment methods on the biohydrogen production potential of mixed microbial consortia.

\section{Materials and methods}

\subsection{Seed sludge and related analytical methods}

Seed sludge was collected from a domestic biogas fermenter processing mainly food waste. To calculate soluble COD, reducing sugar and protein contents, appropriate samples were centrifuged ( $5 \mathrm{~min}, 12,000 \mathrm{rpm}$ ) and then filtered through a $0.45 \mu \mathrm{m}$ pore size membrane disc in order to get rid of the suspended solids. The supernatant obtained was used to determine soluble COD by following the procedure of
APHA [19]. Reducing sugars in the supernatant solution were analyzed by o-toluidine method and expressed as $\mathrm{mg}$ glucose $\mathrm{eqv}^{\mathrm{L}} \mathrm{L}$. The concentration of proteins $(\mathrm{mg} / \mathrm{L})$ in the liquor was estimated based on the Folin reaction.

\subsection{Sludge pretreatment conditions}

Seed inocula were pretreated either by means of conventional and unconventional methods. The exact treatment circumstances are presented in Tables 1 and 3. Conventional thermal curing was carried out in an ordinary water bath with occasional mechanical stirring (30 $\mathrm{s}$ in each $5 \mathrm{~min})$. For unconventional, microwave-aided method a commercially available, lab-scale instrument was used (Discover series, BenchMate model, CEM ${ }_{\Lambda}$ Corp., USA). The device has $5 \mathrm{~mL}$ capacity sealable tubes to treat samples, in our case anaerobic biogas sludge. It is equipped with a magnetic stirrer, able to maintain a constant experimental temperature with the accuracy of $\pm 1{ }^{\circ} \mathrm{C}$ through air cooling and by automatically varying the power output (amount of energy emitted to a certain volume of sample in a given time $-\mathrm{J} / \mathrm{mL}$-s). To attain the desired pretreatment temperatures output power of $100 \mathrm{~W}$ was set as an upper limit. For all the pretreatments (being either conventional or unconventional) the reaction times have started when the samples reached the desired temperature.

\subsection{Hydrogen fermentation experiments}

Biohydrogen production measurements were performed in $100 \mathrm{~mL}$ batch vials sealed by rubber stoppers. $25 \mathrm{~mL}$ working (liquid phase) volume was applied. Initial pHs were set to 6.5 by droplets of $0.5 \mathrm{M} \mathrm{HCl}$. Prior to starting the fermentations, high purity $\mathrm{N}_{2}$ sparging was employed for 5 min to provide a fully anaerobic environment in the bottles. The closed vessels were placed in a reciprocal air-bath shaker at $150 \mathrm{rpm}$ under controlled temperature $\left(37^{\circ} \mathrm{C}\right)$ for $24 \mathrm{~h}$. Potato starch $(5 \mathrm{~g} / \mathrm{L})$ and yeast extract $(2 \mathrm{~g} / \mathrm{L})$ was added to the pretreated inocula as substrate and external nitrogen/mineral source during the experimental runs, respectively.

Determination of biogas produced was checked by glass syringe method after $24 \mathrm{~h}$ when fermentations were over. Headspace gas composition was determined by gas chromatography (HP 5890 gas chromatograph, CarboPlot column $90^{\circ} \mathrm{C}, \mathrm{TCD}-115^{\circ} \mathrm{C}, \mathrm{N}_{2}$ carrier gas).

\section{Table 1 - The pretreatment circumstances applied during} conventional heat shock.

Pretreatment temperature $\left({ }^{\circ} \mathrm{C}\right)$ 
Table 2 - ANOVA table for the conventional heat shock pretreatment.

Dependent variable: $\mathrm{H}_{2}$ productivity $\left(\mathrm{mL} \mathrm{H}_{2} / \mathrm{mL}-\mathrm{d}\right.$ )

Factors $\quad$ Significance value $(p)$

\begin{tabular}{ll} 
(1) Pretreatment time $(\min )$ & 0.09 \\
(2) Pretreatment temperature $\left({ }^{\circ} \mathrm{C}\right)$ & 0.03 \\
1 by 2 & 0.11 \\
Curvature & 0.1 \\
\hline
\end{tabular}

The $\mathrm{H}_{2}$ productivity, soluble COD, reducing sugar and protein content data used for statistical variance analysis (ANOVA) are mathematical averages of triplicates (Tables 1 and 3). Standard deviations were within 5\%. ANOVA was conducted in Statistica 8 software.

\section{Results and discussion}

\subsection{The effect of conventional heat pretreatment on biohydrogen production}

In general, although it seems to be true that conventional heat treatment is an effective procedure to promote hydrogenevolver strains mainly such as Clostridium, the most adequate conditions may vary from one inoculum to another demonstrating that curing temperature and its duration are case-sensitive variables. As a general rule of thumb, it is apparent from the literature that temperature should be chosen in the range of approximately $75-100{ }^{\circ} \mathrm{C}$ while typical treatment times fall within $30 \mathrm{~min}-120 \mathrm{~min}$. This is because methanogenic bacteria cannot survive above $65-70^{\circ} \mathrm{C}$, especially not for prolonged times. However, relationship between pretreatment temperature and time is not frequently addressed. In the present work, both factors were under investigation within the boundaries listed in Table 1.

To reveal their significance, statistical analysis (ANOVA) was performed (Table 2). As it can be seen in Table 2, among the variables studied the pretreatment temperature displayed the higher influence $(p \leq 0.05)$, while the duration of the treatment would appear to be insignificant from statistical point of view $(p>0.05)$. Subsequently, temperature is the factor which plays a more particular role in the effectiveness of the process in comparison with treatment time. Moreover, it is also to see that neither of the interactive effects and nor the curvature are statistically important. The latter means that a linear model would be adequate to describe the pretreatment temperature and time dependency of $\mathrm{H}_{2}$ productivity.

The corresponding three-dimensional response plot visualizing their impacts on biohydrogen productivity can be seen in Fig. 1. These outcomes are in correlation with the findings reported by Baghchehsaraee et al., who clearly demonstrated that heat shock temperature had a notable influence on the achievable hydrogen turnouts and the composition of the microbial consortia, as well [20].

The analysis of Fig. 1 suggests that seed pretreatment should be conducted at lower temperatures since it resulted in higher hydrogen productivity values. This may be attributable to the fact elevated temperatures kill not only the methanogenes but also certain, non-spore forming hydrogen producers such as Enterobacter species, therefore cause a reduction in the useful microbial diversity. This is the reason why the members of (spore-forming) Clostridia are more commonly found as active bacteria in conventionally heat treated inocula.

\subsection{The impact of unconventional, microwave-assisted heat pretreatment on biohydrogen production}

The traditional, convective heat transfer e.g. by means of water bath, electric mantles, etc. is relatively slow and low efficient due to its dependency on the heat conductivity of both the reaction mixture and the vessel containing it. It also suffers from the drawback that a significant temperature gradient may be developed (hotter wall, relatively colder reaction mixture) in the liquor if lacking sufficient mixing, possibly causing overheated microenvironments and concomitant uncertain phenomena. Nevertheless, microwave-based heat transfer represents a more efficient and quicker way in comparison to the normal convective one since it contacts directly with the molecules in the liquid having microwave energy absorption capability. The vessels applied are made of microwave-transparent materials and hence their conductivity is not a factor in the process. Therefore, a reverse temperature profile (hotter reaction mixture, colder vessel wall) can be ensured.

Table 3 - The results of unconventional, microwave-aided heat shock along with the corresponding $\mathrm{H}_{2}$ productivity, soluble COD, reducing sugar and protein values.

\begin{tabular}{|c|c|c|c|c|c|c|}
\hline \multirow[t]{2}{*}{ Run } & \multicolumn{2}{|c|}{ Pretreatment conditions } & \multirow{2}{*}{$\begin{array}{c}\mathrm{H}_{2} \\
\text { productivity } \\
\left(\mathrm{mL} \mathrm{H} \mathrm{H}_{2} / \mathrm{mL}-\mathrm{d}\right)\end{array}$} & \multirow{2}{*}{$\begin{array}{l}\text { Soluble COD } \\
\left(\mathrm{mg} \mathrm{O}_{2} / \mathrm{L}\right)\end{array}$} & \multirow{2}{*}{$\begin{array}{l}\text { Soluble reducing } \\
\text { sugar (mg glucose } \text { eqv} / L)^{\text {(m) }}\end{array}$} & \multirow{2}{*}{$\begin{array}{c}\text { Soluble } \\
\text { proteins (mg/L) }\end{array}$} \\
\hline & Temperature $\left({ }^{\circ} \mathrm{C}\right)$ & Time (min) & & & & \\
\hline A & Untreated seed sludge & & N.T. & 1587 & 93 & 204 \\
\hline B & 70 & 2 & 0.44 & 2128 & 126 & 347 \\
\hline C & 70 & 5 & 0.66 & 4348 & 141 & 563 \\
\hline $\mathrm{D}$ & 80 & 2 & 0.43 & 3915 & 162 & 809 \\
\hline E & 80 & 5 & 0.82 & 5774 & 180 & 980 \\
\hline $\mathrm{F}$ & 80 & 10 & 0.08 & 7239 & 189 & 1124 \\
\hline G & 90 & 5 & 0.84 & 6821 & 201 & 1185 \\
\hline $\mathrm{H}$ & 90 & 10 & 0.14 & 8758 & 219 & 1268 \\
\hline
\end{tabular}




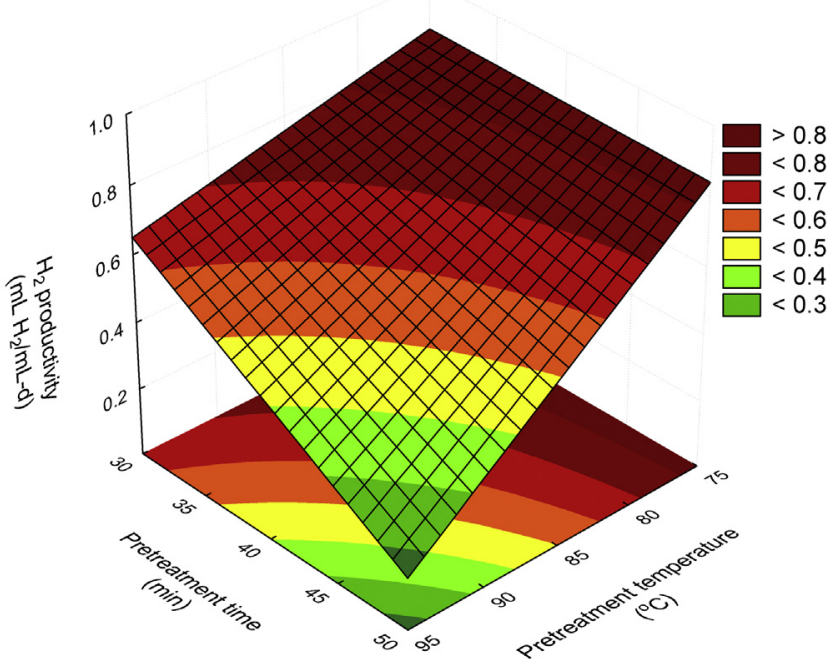

Fig. 1 - The impact of conventional heat pretreatment on biohydrogen productivity.

Consequently, if the microwave reactor is well designed and equipped with proper stirring, an equal temperature could be provided everywhere in the reaction liquor. In other words, the major benefit of microwave heating is the uniformity of heating as well as the adequate control of the process temperature [15].

Due to the above theoretical considerations, it was assumed that sufficient pretreatment efficiency may be achieved in reasonably shorter curing times due to the more intense energy transfer characteristics of microwave irradiation.

The temperatures and treatment times investigated during microwave-assisted heat shock are presented in Table 3.

Discussing the results of the unconventional heat treatment, the first important conclusion is that methane could not be detected in any of the measurements, not even in the cases when the mixed culture was exposed to curing times as extremely short as 2 min. It is in contrast with the conventional heat treatment where - regardless of the temperature setting the duration of the treatment remarkably shorter than $30 \mathrm{~min}$ is expectedly insufficient. This discrepancy can be explained by the different modes of action of the microwaveassisted and the conventional thermal shock.

Emitting microwaves into the culture liquid is considered as a direct and more intense way of energy input as compared to normal heat shock, which probably leads to an improved heating efficiency and a prompter observable effect. Consequently, it may allow one to achieve a successful, heat-based selection of the hydrogen-forming microorganisms in significantly reduced times. The ANOVA-based evaluation of the experimental data can be seen in Table 4. The impact of microwave-aided heat pretreatment taking $\mathrm{H}_{2}$ productivity as response variable is depicted in Fig. 2.

According to Table 4 it seems that pretreatment time rather than temperature is considered as the key factor influencing the attainable hydrogen productivity. This outcome is in contrast with the traditional heat shock where temperature could be identified as the statistically important process variable. It implies that, as stated above, conventional and unconventional methods possess distinct features. Furthermore, it is shown in Fig. 2 that regardless of the temperature, increasing treatment time from 2 to 5 min resulted in an enhanced hydrogen production. However, further increment from 5 to $10 \mathrm{~min}$ caused an apparent decrease in the $\mathrm{H}_{2}$ generation efficiency. Such tendency may be correlated with the amount of energy delivered to the culture. In cases where treatment durations exceeded 5 min it is assumed that not only the $\mathrm{H}_{2}$-consuming but also the more robust $\mathrm{H}_{2}$ producing strains might have been inhibited or eliminated. It may be a reasonable explanation if taking into account that high power densities/inputs can cause the lysis of the cells. When a drastic lysis of the cells occurs because of the harsh ambient conditions (as assumed $>5$ min pretreatment times), it inevitably reduces the number of potential hydrogen producer bacteria in the culture and concurrently depresses the hydrogen formation capacity, as well.

Therefore, it would be interesting to check the changes in the microbial population before and after the various pretreatment conditions e.g. by PCR-DGGE, T-RFLP or FISH $[21,22]$ which can be a subject for a future investigation. In addition to monitoring the bacterial community structure, the analysis of the soluble metabolic products (e.g. volatile fatty acids) in the fermentation broth may yield some basic information about the occurring shifts in the dominant metabolic pathways upon (microwave irradiation) seed pretreatment.

So far, Song and coworkers investigated the alterations in microbial diversity after microwave pretreatment by PCRDGGE technique [13]. It was found that only some microwave tolerant species could survive the irradiation, the others were sufficiently inhibited. In that study, cow dung compost as seed source was irradiated with microwave energy and then employed in a dark fermentative biohydrogen process using corn stalk as substrate. Their findings are in good agreement with our current results, since they reported that radiation time (between 0 and $\Lambda^{2.5}$ min) strongly

Table 4 - ANOVA table for the unconventional, microwave-based heat shock pretreatment.

Dependent variable

\begin{tabular}{|c|c|c|c|c|}
\hline \multirow[t]{3}{*}{ Factors } & \multicolumn{4}{|c|}{ Dependent variable } \\
\hline & $\mathrm{H}_{2}$ productivity & Soluble COD & Soluble reducing sugars & \multirow[t]{2}{*}{ Soluble proteins } \\
\hline & \multicolumn{3}{|c|}{ Significance value $(p)$} & \\
\hline$(\mathrm{L}+\mathrm{Q})$ pretreatment time & 0.013 & 0.011 & 0.007 & 0.003 \\
\hline$(\mathrm{L}+\mathrm{Q})$ pretreatment temperature & 0.362 & 0.02 & 0.03 & 0.015 \\
\hline
\end{tabular}




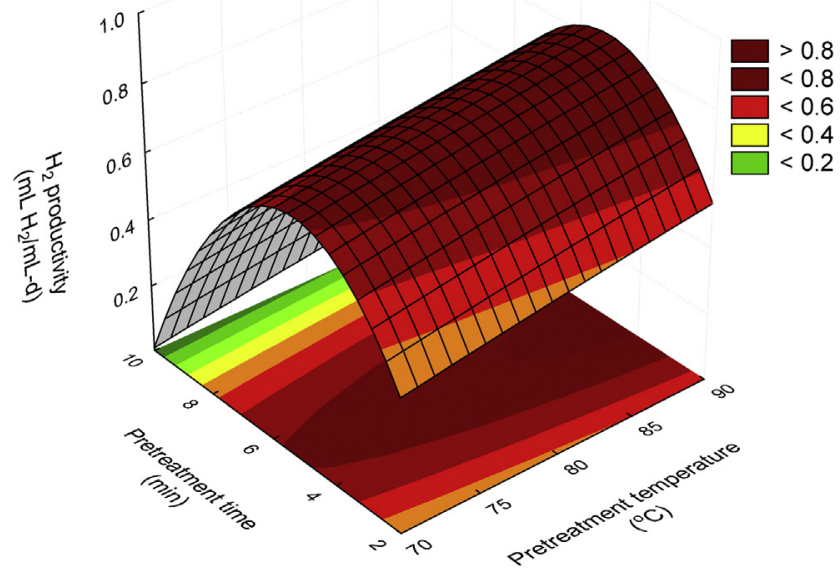

Fig. 2 - Response plot demonstrating the effects of microwave-assisted heat thermal pretreatment on hydrogen productivity.

influenced the hydrogen production activity. In fact, a similar pattern to the one demonstrated in Fig. 2 was observed since increased curing times up to $1.5 \mathrm{~min}$ resulted in higher hydrogen turnouts, while declined values were obtained at more prolonged irradiations. Another important conclusion to be drawn is that extremely short irradiation times - even below 2 min - were satisfactory to enrich hydrogen-evolver strains, which is in accordance with our present observations [13].

As a summary of biohydrogen fermentation by conventionally and unconventionally heat treatment inocula, it can be concluded that microwave irradiation considerably reduced the essential sludge pretreatment times, however, the accomplishable $\mathrm{H}_{2}$ productivity values in both cases remained quite comparable (as high as $0.9 \mathrm{~mL} \mathrm{H} / \mathrm{mL}-\mathrm{d}$ ), as can be seen in Figs. 1 and 2. It is to admit that the productivities obtained in this study are not highly attractive ones, but the focus was on the comparative assessment of the two alternative heat treatment procedures rather than on comprehensive process intensification.

3.3. The effect of microwave irradiation on various characteristics of the pretreated inocula

A series of measurements were carried out in order get a better understanding about the possible changes taking place in the particular sludge as a result of microwave irradiation. The pretreated samples were conditioned as described in the Materials and Methods section (centrifuged and subsequently membrane filtered) and subjected to visual inspection (Fig. 3).

As it can be clearly seen in Fig. 3, the colors of the samples have significantly been changed as a consequence of the pretreatment conditions. In fact, regarding the optical features it can be concluded that the supernatants obtained

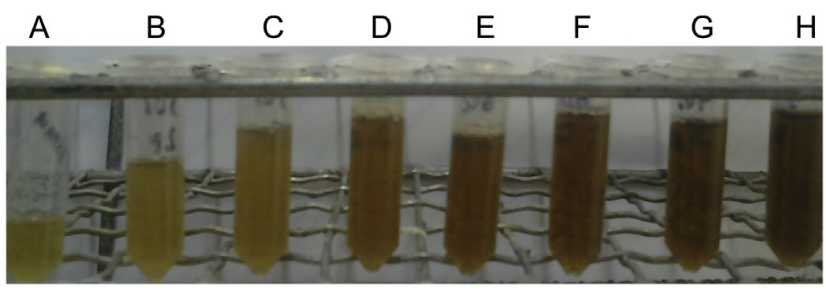

Fig. 3 - The supernatants of microwave pretreated samples (Codes of the samples ( $\mathbf{A}-\mathbf{H})$ appear in Table 3 ). (For interpretation of the references to color in this figure legend, the reader is referred to the web version of this article.)

started to become darker as the curing time and temperature have been raised.

Microwave irradiation can be applied to pretreat complex feedstock (e.g. lignocellulosic) in order to enhance the accessibility of biological catalysts to the structural regions of interest of the substrate and to liberate simpler, bioconvertable substances from polymer molecules. In other words, microwave irradiation likely aid the solubilization of organic matter [16-18,23]. In addition, there are methods relying on microwave energy with the aim of sludge conditioning [24-30].

It is known that any kind of sludge taken e.g. from an anaerobic fermenter - depending on the nature of its raw material - inherently comprises insoluble, persistent constituents which may be made solubilized by means of microwave energy. Based on these facts, it was assumed that the change in the color of the samples might have occurred due to the increased amount of soluble substances in the liquid. To support this theory, the chemical oxygen demand of the pretreated, centrifuged samples was measured. It is a good indicator of organic matter content and feasible to check the trend in its release upon different irradiation circumstances. The soluble COD (SCOD) profiles of the unconventionally heat

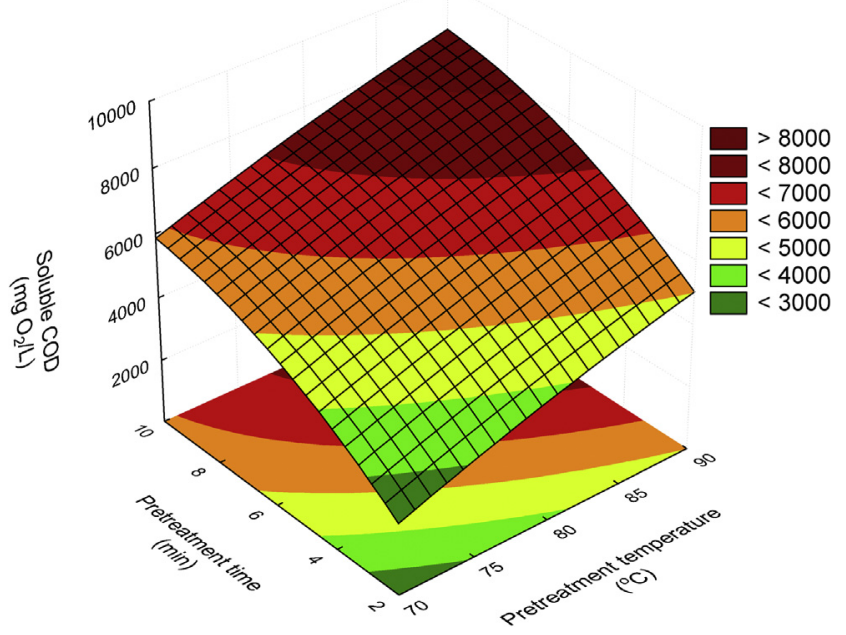

Fig. 4 - Response surface illustrating the change in soluble COD content as a result of the microwave-assisted thermal sludge pretreatment.

66

67

68

69

70

71

72 
pretreated seed inocula are given in Table 3 and graphically interpreted in Fig. 4.

The statistical assessment of the SCOD measurements in Table 4 demonstrates well that both the pretreatment temperature and its duration had a strongly significant effect on the soluble organic matter content. Hence, it would appear that by using microwave heating not only the desired group of hydrogen-evolver microorganisms can be promoted but it is also possible to simultaneously increase the soluble organic fraction in the seed inocula. For instance, in the work by Song et al. microwave pretreatment time (between 0 and 2.5 min) strongly influenced the volatile suspended solid (VSS) concentration. The VSS fraction in a liquid mixture is in a direct relationship with the organic fraction of the suspended solids. According to their outcomes, VSS concentration has been enhanced over a wide range of pretreatment times tested (between 0 and 2 min) [13].

In general, derivatives of sugars, proteins and fats are among the main constituents of the anaerobic sludge, their ratios are certainly the function of the feed composition. To get a better picture about the change in SCOD reducing sugar and protein contents were also estimated. The results are indicated in Fig. 5 and 6, which together with the ANOVA data in Table 4 confirmed that the temperature and the irradiation time of microwave pretreatment could enhance the reducing sugar and the protein concentrations in the soluble phase. It can be also pointed out that the pattern of reducing sugar and protein release is similar to that of the SCOD, proving a reasonable relationship between them.

It is also to note that the concentration of proteins was apparently higher as compared to reducing sugars. As a consequence, it is implied that proteins rather than reducing sugars contributed to the increment of SCOD along the pretreatment conditions. These findings are in good agreement with the one obtained by Thungklin et al. who also reported that proteins were the dominant soluble organic materials upon exposing the sludge to microwave irradiation [31]. In addition, as it could be concluded, the ratio of the various substances released as a result of the microwave-assisted

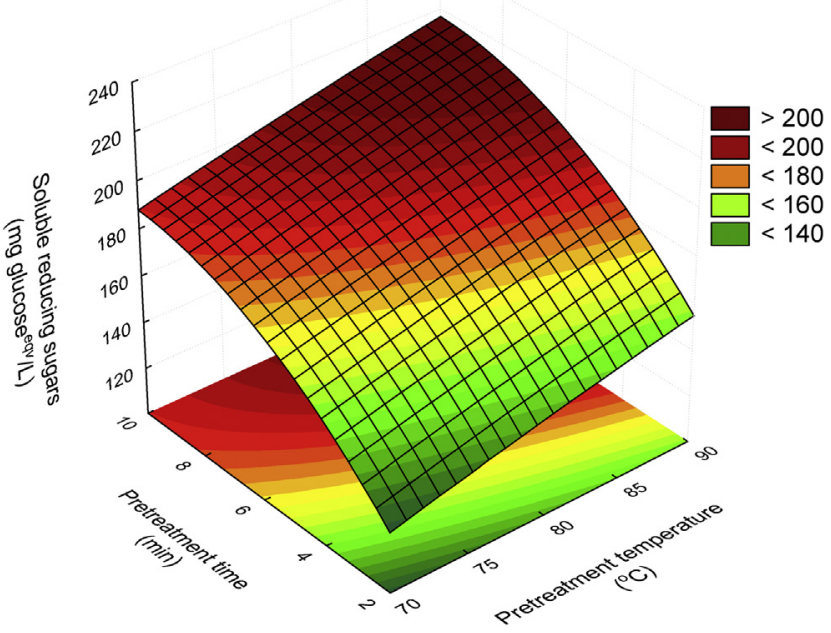

Fig. 5 - The correlation between microwave pretreatment conditions and soluble reducing sugars.

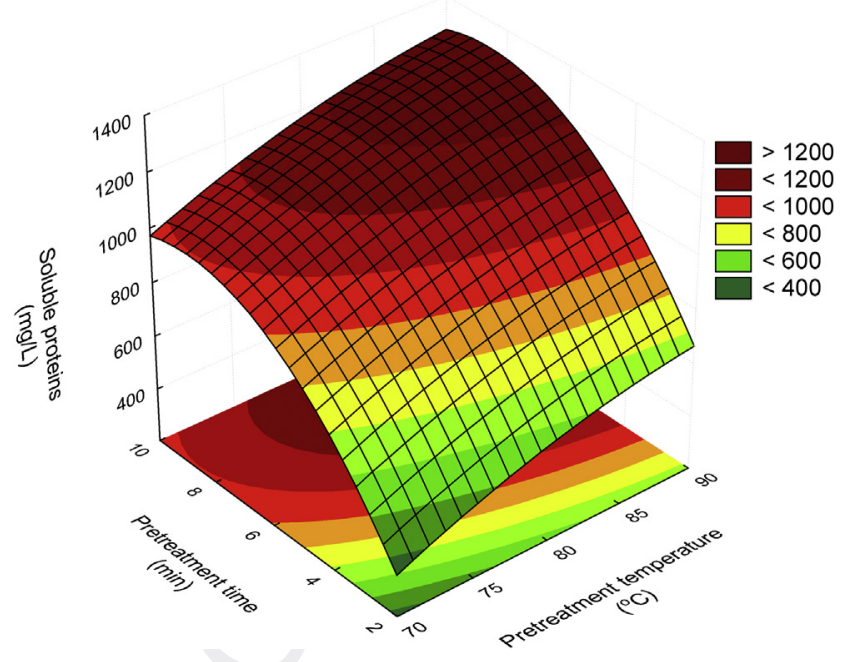

Fig. 6 - The relationship of microwave pretreatment conditions and soluble protein concentration.

treatment demonstrates a functionality ${ }_{\Lambda}$ on the source of the sludge.

Moreover, the lysis of cells upon harsh environmental (here microwave pretreatment) conditions can also potentially affect the soluble organic matter content in the anaerobic seed sludge. It is due to the liberation of extracellular and intracellular biopolymers and nutrients such as carbohydrates, proteins and lipids into the solution and is also a consequence of pronounced solubilization of insoluble, particulate organic substances [32].

Regarding the mechanism of cell lysis during external energy irradiation, some observations may be adopted from ultrasonication related literature [33]. It has been found that certain treatment times and power intensities applied can lead to the disintegration of cell in the sludge [34]. However, strains may be simply inactivated prior to cell wall breakage taking place [35], meaning that an increased soluble COD could be an indicator of cell disruption, but not necessarily is [36]. Therefore, the strong depressions in hydrogen productivity (Fig. 2) might have been due to cell rupture or inactivation of microbes, or both.

As referenced above in the manuscript, contacting the sludge with microwaves can alter its characteristics, and this technique is often used for waste sludge minimization purposes. In such cases, the sludge does not play the role of inocula source but rather it is utilized as a feedstock for certain bioconversions e.g. during anaerobic digestion.

For example, Park et al. studied the impact of microwave irradiation on the solubilization of waste-activated sludge. It was demonstrated that both pretreatment temperature and power output could significantly enhance the extent of hydrolysis (higher soluble COD and total COD ratios), which is expected to bring improved digestibility and concurrently increased biogas capacities [37].

However, it has been proven by Eskicioglu and coworkers that even if the microwave pretreatment does not help the release of organic compounds in a distinguishable manner compared to traditional convective heating, the former can surpass in the view of biogas producing potential. It is 
attributable to the so-called athermal effect of microwave contact [38].

Furthermore, Thungklin et al. [31] and Guo et al. [39] demonstrated that waste sludge pretreated by the contribution of microwave energy can be a feasible raw material not only for biogas, but for biohydrogen fermentation, as well.

\section{Conclusions}

In this work, a comparative assessment on conventional and unconventional (microwave-assisted) heat pretreatment methods was carried to enrich biohydrogen producing strains. It has turned out that hydrogen productivity was significantly affected by pretreatment temperature when the conventionally treated seed inoculum was used. On the other hand, in case of the microwave-supported process $\mathrm{H}_{2}$ capacity showed a more pronounced dependency on treatment time rather than on temperature. This contradictory behavior might have been due to the different modes of actions of the two heat transfer techniques. As a result, normal- and microwave-based heat pretreatments resulted in seeds with comparable hydrogen producing potentials. Nevertheless, unconventional heat pretreatment considerably reduced the necessary curing times for the suppression of methanogenic activity. Furthermore, microwave irradiation notably increased the soluble organic matter content of the pretreated seed sludge.

\section{Acknowledgments}

This work was supported by the European Union and financed by the European Social Fund in the frame of the TAMOP-4.2.2/ A-11/1/KONV-2012-0071 project and the János Bolyai Research Scholarship of the Hungarian Academy of Sciences.

\section{R E F E R E N C E S}

[1] Das D, Veziroglu TN. Advances in biological hydrogen production processes. Int J Hydrogen Energy 2008;33:6046-57.

[2] Winter CJ. Hydrogen energy - abundant, efficient, clean: a debate over the energy-system-of-change. Int J Hydrogen Energy 2009;34:S1-52.

[3] Hawkes F, Dinsdale R, Hawkes DL, Hussy I. Sustainable fermentative hydrogen production: challenges for process optimization. Int J Hydrogen Energy 2002;27:1339-47.

[4] Nath K, Das D. Improvement of fermentative hydrogen production: various approaches. Appl Microbiol Biotechnol 2004;65:520-9.

[5] Bakonyi P, Nemestóthy N, Bélafi-Bakó K. Biohydrogen purification by membranes: an overview on the operational conditions affecting the performance of non-porous, polymeric and ionic liquid based gas separation membranes. Int J Hydrogen Energy 2013;38:9673-87.

[6] Ramírez-Morales JE, Tapia-Venegas E, Nemestóthy N, Bakonyi P, Bélafi-Bakó K, Ruiz-Filippi G. Evaluation of two gas membrane modules for fermentative hydrogen separation. Int J Hydrogen Energy 2013;38:14042-52.
[7] Kapdan IK, Kargi F. Bio-hydrogen production from waste materials. Enzyme Microb Technol 2006;38:569-82.

[8] Sinha P, Pandey A. An evaluative report and challenges for fermentative biohydrogen production. Int J Hydrogen Energy 2011;36:7460-78.

[9] Cheng CL, Lo YC, Lee KS, Lee DJ, Lin CY, Chang JS. Biohydrogen production from lignocellulosic feedstock. Bioresour Technol 2011;102:8514-23.

[10] Lin CY, Lay CH, Sen B, Chub CY, Kumar G, Chene CC, et al. Fermentative hydrogen production from wastewaters: a review and prognosis. Int J Hydrogen Energy 2012;37:15632-42.

[11] Rittmann S, Herwig C. A comprehensive and quantitative review of dark fermentative biohydrogen production. Microb Cell Fact 2012;11:115-33.

[12] Wang J, Wan W. Factors influencing fermentative hydrogen production: a review. Int J Hydrogen Energy 2009;34:799-811.

[13] Song ZX, Wang ZY, Wu LY, Fan YT, Hou HW. Effect of microwave irradiation pretreatment of cow dung compost on bio-hydrogen process from corn stalk by dark fermentation. Int J Hydrogen Energy 2012;37:6554-61.

[14] Kappe CO. Microwave assisted chemistry. Compr Med Chem 2007;3:837-60.

[15] Major B, Nemestóthy N, Bélafi-Bakó K, Gubicza L. Enzymatic esterification of lactic acid under microwave conditions in ionic liquids. Hung J Ind Chem 2008;36:77-81.

[16] Liu CZ, Cheng XY. Improved hydrogen production via thermophilic fermentation of corn stover by microwaveassisted acid pretreatment. Int J Hydrogen Energy 2010;35:8945-52.

[17] Zhu SD, Wu YX, Yu ZN, Liao JT, Zhang Y. Pretreatment by microwave/alkali of rice straw and its enzymic hydrolysis. Process Biochem 2005;40:3082-6.

[18] Zhu SD, Wu YX, Yu ZN, Wang CW, Yu FQ, Jin SW, et al. Comparison of three microwave/chemical pretreatment processes for enzymatic hydrolysis of rice straw. Biosyst Eng 2006;93:279-83.

[19] APHA. Standard methods for the examination of water and wastewater. 19th ed. New York, USA: American Public Health Association; 1995.

[20] Baghchehsaraee B, Nakhla G, Karamanev D, Margaritis A, Reid G. The effect of heat pretreatment temperature on fermentative hydrogen production using mixed cultures. Int J Hydrogen Energy 2008;33:4064-73.

[21] Tolvanen KES, Karp MT. Molecular methods for characterizing mixed microbial communities in hydrogenfermenting systems. Int J Hydrogen Energy 2011;36:5280-8.

[22] Li RY, Zhang T, Fang HHP. Application of molecular techniques on heterotrophic hydrogen production research. Bioresour Technol 2011;102:8445-56.

[23] Binod P, Satyanagalakshmi K, Sindhu R, Janu KU, Sukumaran RK, Pandey A. Short duration microwave assisted pretreatment enhances the enzymatic saccharification and fermentable sugar yield from sugarcane bagasse. Renew Energy 2012;37:109-16.

[24] Sólyom K, Mato RB, Pérez-Elvira SI, Cocero MJ. The influence of the energy absorbed from microwave pretreatment on biogas production from secondary wastewater sludge. Bioresour Technol 2011;102:10849-54.

[25] Yu Q, Lei H, Yu G, Feng X, Li Z, Wu Z. Influence of microwave irradiation on sludge dewaterability. Chem Eng J 2009;155:88-93.

[26] Yu Q, Lei HY, Li Z, Li HL, Chen $\mathrm{K}$, Zhang XH, et al. Physical and chemical properties of waste-activated sludge after microwave treatment. Water Res 2010;44:2841-9.

[27] Chang CJ, Tyagi VK, Lo SL. Effects of microwave and alkali induced pretreatment on sludge solubilization and 
8

INTERNATIONAL JOURNAL OF HYDROGEN ENERGYXXX（2OI4) I-8

subsequent aerobic digestion. Bioresour Technol 2011;102:7633-40.

[28] Wojciechowska E. Application of microwaves for sewage sludge conditioning. Water Res 2005;39:4749-54.

[29] Logan I, Sain FD. Alkaline solubilization and microwave irradiation as a combined sludge disintegration and minimization method. Water Res 2009;43:2139-48.

[30] Beszédes S, László Z, Horváth ZH, Szabó G, Hodúr C. Comparison of the effects of microwave irradiation with different intensities on the biodegradability of sludge from dairy- and meat-industry. Bioresour Techno 2011;102:814-21.

[31] Thungklin P, Reungsang A, Sittijunda S. Hydrogen production from sludge of poultry slaughterhouse wastewater treatment plant pretreated with microwave. Int J Hydrogen Energy 2011;36:8751-7.

[32] Eskicioglu C, Kennedy KJ, Droste RL. Characterization of soluble organic matter of waste activated sludge before and after thermal pretreatment. Water Res 2006;40:3725-36.

[33] Carrére H, Dumas C, Battimelli A, Batstone DJ, Delgenčs JP, Steyer JP, et al. Pretreatment methods to improve sludge anaerobic degradability: a review. J Hazard Mater 2010;183:1-15.

[34] Thu CP, Lee DJ, Chang BV, You CS, Thy JH. Weak ultrasonic pretreatment on anaerobic digestion of flocculated activated biosolids. Water Res 2002;36:2681-8.

[35] Salsabil MR, Prorot A, Canellas M, Dagot C. Pre-treatment of activated sludge: effect of sonication on aerobic and anaerobic digestibility. Chem Eng J 2009;148:327-35.

[36] Li H, Jun Y, Mahar RB, Wang Z, Ne Y. Effects of ultrasonic disintegration on sludge microbial activity and dewaterability. J Hazard Mater 2009;161:1421-6.

Q1

[37] Park WJ, An JH, Hwang S, Lee CK. Effect of output power, target temperature, and solid concentration on the solubilization of waste activated sludge using microwave irradiation. Bioresour Technol 2010;101:S13-6.

[38] Eskicioglu C, Terzian N, Kennedy KJ, Droste LR, Hamoda M. Athermal microwave effects for enhancing digestibility of waste activated sludge. Water Res 2007;41:2457-66.

[39] Gro L, Li XM, Bo X, Yang Q, Zens GM, Liao DX, et al. Impacts of sterilization, microwave and ultrasonication pretreatment on hydrogen producing using waste sludge. Bioresour Technol 2008;99:3651-8.
24
25
26
27
28
29
30
31
32
33
34
35
36
37
38
39
40
41
42
43
44
45
46

Please cite this article in press as: Bakonyi $\mathrm{P}$, et al., Fermentative hydrogen production by conventionally and unconventionally heat pretreated seed cultures: A comparative assessment, International Journal of Hydrogen Energy (2014), http://dx.doi.org/ 10.1016/j.ijhydene.2014.01.110 